9. Мильнер-Иринин Я.А. Этика, или Принципы истинной человечности. М.: Наука, 1999. 520 с.

10. Вершинина Л.В. Теоретические основы формирования ценностного сознания будущего учителя. М.: МПСИ, 2009. 258 с.

11. Лопухова Ю.В. Теоретические основы воспитания толерантности студентов вуза. М.: Московский психолого-социальный университет, 2012. 197 с.

12. Выжлецов Г.П. Аксиология культуры. СПб.: СПбГУ, 1996. 152 с.

13. Гусейнов А.А., Апресян Р.Г. Этика. М.: Гардарики, 2007. 472 с.

14. Братусь Б.С. Личностные смыслы по А.Н. Леонтьеву и проблема вертикали сознания // Традиции и перспективы деятельностного подхода в психологии: школа А.Н. Леонтьева. М.: Смысл, 1999. С. 284 298.

15. Соловьев В.С. Оправдание добра: нравственная философия. М.: Республика, 1996. 479 с.

16. Лосский Н.О. Условия абсолютного добра. М.: Политиздат, 1991. 368 с.

17. Бездухов А.В. О концепции формирования этического сознания будущего учителя // Известия
Самарского научного центра Российской академии наук. 2014. Т. 16, № 2. С. 29-33.

18. Шрейдер Ю.А. Этика. М.: Текст, 1998. 271 с.

19. Салов А.И. Морально-этические принципы как предмет педагогической рефлексии // Самарский научный вестник. 2016. № 3 (16). С. 189-194.

20. Позднякова О.К. Теоретические основы формирования нравственного сознания будущего учителя. М.: МПСИ, 2006. 168 с.

21. Бездухов В.П., Позднякова О.К. Этико-педагогический подход к формированию ценностных ориентаций будущего учителя и принципы его реализации // Педагогика. 2010. № 6. С. 15-26.

22. Скворцов А.А. Этика. М.: Юрай, 2012. 306 с.

23. Момов В. Теоретические проблемы нравственного воспитания // Предмет и система этики. М.: Институт философии АН СССР; София: Институт философии БАН, 1973. С. 323-345.

24. Юдин Э.Г. Методология науки. Системность. Деятельность. М.: Эдиториал УРСС, 1997. 444 с.

25. Бездухов А.В. Структура этического сознание учителя // Вестник Тверского государственного университета. 2013. № 26. Серия «Педагогика и психология». Вып. 4. С. 254-263.

\title{
THE CONCEPT OF THE TEACHER'S ETHICAL WORLDVIEW FORMATION
}

(C) 2017

Salov Alexander Igorevich, candidate of pedagogical sciences, associate professor, rector Academy of Public Administration (Moscow, Russian Federation)

\footnotetext{
Abstract. The paper shows the importance of an ethical world view, which is a kind of «technology» for eliminating the worst enemies of mankind (terrorism, separatism, etc.), the «technology» of survival in situations that go beyond everyday life, leading to a common moral and ethical denominator of people's efforts to suppress evil; it is pointed out that the ethical worldview of the teacher is a system of «values of values» as the ultimate meanings of life and activity that are directed towards the moral and value reality of the vertical of ethical consciousness, acting in the form of guidelines on the path of movement toward moral ideals, on top of which there is the ideal of «the man of Mankind»; different points of view of scientists as to their understanding of the concept «concept» are being comprehended; the concept of the formation of the ethical worldview of the teacher in the process of improving the pedagogical qualification is developed in the following logic: 1 . The rationale for the idea a) being the backbone of the transition from the core of the ethical worldview of the teacher of basic values to the goal; b) unfolding into the ideal as an image of the desired. 2. Defining the goal within the transition from basic values to the idea. 3. Justification of the ideal, the approach to which the teacher, the student is carried out through the good, synthesizing the basic values. 4. Identification of moral and ethical principles for the formation of the ethical worldview of the teacher. 5. Defining the approach to the formation of an ethical worldview teacher.

Keywords: teacher; ethical world view; formation; concept; «values of values»; meaning of life; goodness; virtue; idea; purpose; ideal; «man of Mankind»; moral and ethical principle; ethic-pedagogical approach; content; purpose; essence.
}

\section{ПОЛИФУНКЦИОНАЛЬНАЯ ПОДГОТОВКА БУДУЩИХ УЧИТЕЛЕЙ В КОНТЕКСТЕ ФЕДЕРАЛЬНЫХ ГОСУДАРСТВЕННЫХ ОБРАЗОВАТЕЛЬНЫХ СТАНДАРТОВ И ПРОФЕССИОНАЛЬНОГО СТАНДАРТА ПЕДАГОГА}

\footnotetext{
Семенов Александр Алексеевич, кандидат биологических наук, доцент, заведующий кафедрой биологии, экологии и методики обучения Соловьева Вера Валентиновна, доктор биологических наук, профессор кафедры биологии, экологии и методики обучения
}

Яицкий Андрей Степанович, старший преподаватель кафедры биологии, экологии и методики обучения Самарский государственный соџиально-педагогический университет (2. Самара, Российская Федераџия)

Аннотащия. Педагогическая деятельность носит полифункциональный характер. Полифункциональность деятельности педагога продиктована требованиями федеральных государственных образовательных стан- 
дартов высшего образования и профессиональным стандартом педагога. Под полифункциональной подготовкой будущих учителей подразумевается процесс и результат овладения бакалаврами и магистрами педагогического образования комплексом компетенций, направленных на выполнение различных функций педагога. Выделено 6 основных функций современного учителя: педагогическая, проектная, исследовательская, методическая, управленческая и культурно-просветительская. Педагогическая функция имеет сложную структуру и включает в себя ряд других функций - обучающую, воспитательную, развивающую и коррекционную. Все функции взаимосвязаны между собой. Дана их характеристика. Описан опыт подготовки будущих учителей на естественно-географическом факультете Самарского государственного-педагогического университета в рамках программ бакалавриата и магистратуры педагогического образования. Он состоит в обновлении содержания реализуемых курсов по выбору студентов, разработке и внедрении новых, организации и проведении учебных и производственных практик, учебно- и научно-исследовательской работы студентов, научных конференций, студенческих конкурсов и олимпиад, издании сборников научных трудов, в том числе студенческих. Представлены результаты анкетирования выпускников о качестве их подготовки к выполнению различных функций педагога.

Ключевые слова: педагогическое образование; полифункциональность; полифункциональная подготовка; будущие учителя; бакалавры; магистры; студенты; педагогическая деятельность; педагог; учитель; функции педагога; федеральный государственный стандарт высшего образования; профессиональный стандарт педагога.

Отличительной особенностью современного образования и профессиональной деятельности педагога в России является их стандартизация $[1,2,3,4,5]$.

Установление федеральных государственных образовательных стандартов (ФГОС) - прерогатива государства, закрепленная за ним в статье 43 Конституции Российской Федерации [6].

ФГОС представляет собой совокупность требований к образованию определенного уровня и (или) к профессии, специальности и направлению подготовки [7].

В настоящее время обучение студентов по направлению подготовки «Педагогическое образование» осуществляется на основе федеральных государственных образовательных стандартов высшего образования третьего «плюс» поколения (ФГОС ВО $3+)$. Они направлены на подготовку выпускников к осуществлению следующих видов профессиональной деятельности: педагогическая, проектная, исследовательская (научно-исследовательская), методическая, управленческая и культурно-просветительская. Высшее учебное заведение вправе выбирать виды профессиональной деятельности, к которым будет готовить своих выпускников, исходя из своих возможностей и потребностей рынка труда $[3,4,5]$.

На естественно-географическом факультете (ЕГФ) Самарского государственного социально-педагогического университета (СГСПУ) реализуются программы бакалавриата педагогического образования по профилям «Биология», «География», «Биология и География», «Биология и Химия», «Естествознание», которые готовят выпускников к педагогическому, проектному, исследовательскому (научно-исследовательскому) и культурно-просветительскому видам профессиональной деятельности, а также программы магистратуры педагогического образования «Биологическое образование», «Химическое образование», «Географическое образование», «Управление учебно-воспитательным процессом в системе общего образования». В зависимости от магистерской программы подготовка выпускников ведется к педагогическому, научно-исследовательскому, проектному, методическому и управленческому видам профессиональной деятельности.

Подготовка будущих учителей невозможна в отрыве от профессионального стандарта педагога [2].
Профстандарт имеет рамочный вид. В нем прописаны обобщенные трудовые функции, трудовые функции, требования к образованию педагога и обучению, опыту практической работы; указаны особые условия допуска к работе; перечислены трудовые действия, необходимые умения и знания, приведены другие характеристики. Предполагалось, что профессиональный стандарт педагога вступит в силу с 1 января 2017 года. Однако его введение отложено до 1 сентября 2019 года (приказ Минтруда России от 15.12.2016 г. № 745н). В настоящее время активно обсуждается проект уровневого профессионального стандарта педагога, разработанный в соответствии с Национальной системой учительского роста, который включает в себя состав обобщенных трудовых функций, трудовых функций и перечень трудовых действий согласно уровням учительского роста учитель, старший учитель (первая категория) и ведущий учитель (высшая категория) [1].

Исходя из требований ФГОС ВО 3+ по направлению подготовки «Педагогическое образование» $[3,4$, 5], профессионального стандарта педагога [1, 2], видно, что педагогическая деятельность носит полифункциональный характер.

Вопросы полифункциональности деятельности педагога и полифункциональной подготовки будущих учителей находят свое отражение в работах О.В. Галустян [8], Ю.А. Гончаровой [9], О.С. Жарковой [10], Т.В. Кашликовой [11], Н.В. Кузьминой [12], Т.Ю. Основиной [13], А.Б. Печерской [14], Н.А. Рыкова [15], С. Хасанова [16], О.М. Чоросовой [17], А.И. Щербакова [15] и других авторов.

Полифункциональная подготовка будущих учителей есть процесс и результат овладения бакалаврами и магистрами педагогического образования комплексом компетенций, направленных на выполнение различных функций педагога.

Можно выделить 6 основных функций в подготовке современного учителя: педагогическая, проектная, исследовательская, методическая, управленческая и культурно-просветительская (рис. 1). Ниже рассмотрим эти функции и подготовку к их осуществлению на примере студентов ЕГФ СГСПУ.

Педагогическая функция направлена на изучение возможностей, потребностей и достижений учащихся в области образования; формирование образо- 
Семенов А.А., Соловьева В.В., Яицкий А.С.

вательной среды для обеспечения качества образования; организацию образовательного процесса с применением адекватных образовательных технологий, в том числе информационных, в соответствии с требованиями федеральных государственных образовательных стандартов общего образования, во взаимодействии с коллегами, родителями (законными представителями) и социальными партнерами, обеспечивая сохранность жизни и здоровья учащихся; оценку образовательных результатов; организацию взаимодействия учащихся с соблюдением норм уважительного отношения и правил поведения в процессе образования; создание инклюзивной и мотивирующей образовательной среды.

Педагогическая функция учителя многогранна и включает в себя ряд других функций, таких как обучающая, воспитательная, развивающая, коррекционная.

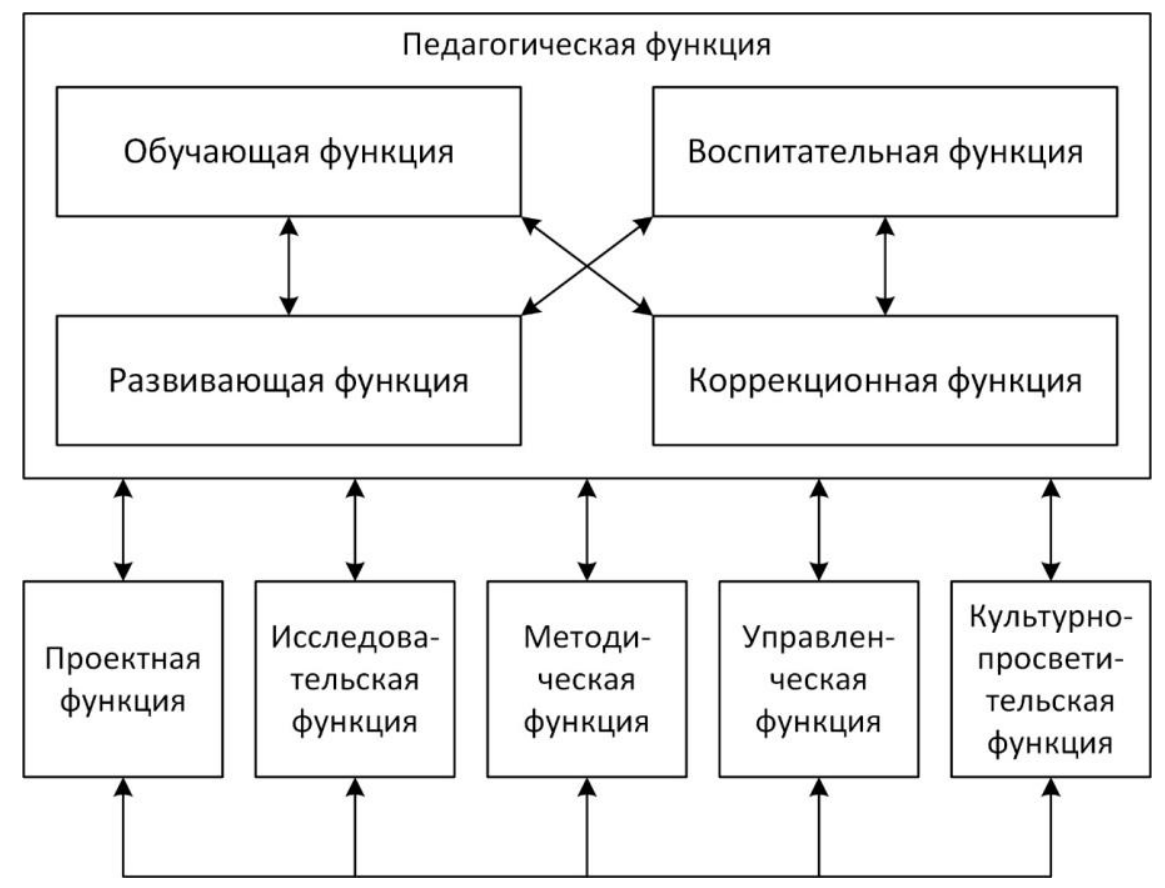

Рисунок 1 - Основные функции учителя общеобразовательной организации

Обучающия функиия связана с реализацией учебных программ; планированием и проведением учебных занятий с использованием информационнокоммуникационных и других технологий с целью овладения учащимися знаниями, умениями, навыками и компетенцией, приобретения опыта деятельности и применения знаний в повседневной жизни; формированием мотивации к обучению и получению образования в течение всей жизни; организацией и осуществлением контроля и оценки учебных достижений.

Воспитательная функция нацелена на реализацию воспитательных программ и мероприятий; воспитание личности учащихся в единстве урочной и внеурочной деятельности с применением современных форм и методов воспитательной работы; реализация воспитательных возможностей учебных дисциплин и различных видов деятельности; создание условий для самоопределения и социализации учащихся на основе социокультурных, духовно-нравственных ценностей и принятых в обществе правил и норм поведения в интересах человека, семьи, общества и государства; использование воспитательных усилий родителей (законных представителей) учащихся и помощь семье в решении вопросов воспитания детей.

Развивающая функиия предполагает развитие способностей и личностных качеств учащихся; формирование и реализацию программы развития универсальных учебных действий; выявление поведенческих и личностных проблем учащихся, связанных с особенностями их развития; освоение и примене- ние развивающих технологий; применение инструментария, методов диагностики и оценки показателей уровня и динамики развития учащихся.

Коррекционная функция подразумевает реализацию программы коррекционной работы; освоение и применение специальных технологий и методов, позволяющих проводить коррекционно-развивающую работу с учащимися, имеющими ограниченные возможности здоровья; оказание адресной помощи учащимся; взаимодействие с другими специалистами в рамках психолого-медико-педагогического консилиума; совместную разработку с другими специалистами и реализацию совместно с родителями (законными представителями) программ индивидуального развития детей.

Проектная функция сосредоточена на проектировании образовательных и просветительских программ, индивидуальных образовательных маршрутов учащихся; проектировании содержания учебных дисциплин, элективных курсов и курсов по выбору учащихся, современных педагогических технологий, образовательных задач, форм и методов контроля и диагностики образовательных результатов, а также контрольно-измерительных материалов; проектировании образовательных сред с целью обеспечения качества образования; проектировании собственного образовательного маршрута и профессиональной карьеры.

Исследовательская функция связана с постановкой и решением исследовательских задач в области науки и образования с использованием современных научных методов и технологий; применени- 
ем в педагогической практике методов научного исследования, в том числе в процессе руководства учебно-исследовательской деятельностью учащихся.

Методическая функция направлена на изучение и анализ профессиональных, образовательных потребностей и возможностей педагогов и проектирование на основе полученных результатов маршрутов индивидуального методического сопровождения; исследование, организацию и оценку реализации результатов методического сопровождения учителей.

Управленческая функция состоит в изучении состояния и потенциала управляемой системы и ее макро- и микроокружения на основе применения методов стратегического и операционного анализа; исследовании, организации и оценке реализации результатов управленческого процесса с использованием технологий менеджмента, соответствующих общим и специфическим закономерностям развития управляемой системы; использовании имеющихся возможностей окружения управляемой системы и проектирование путей ее обогащения и развития для обеспечения качества управления.

Культурно-просветительская функция заключается в изучении и формировании потребностей учащихся и взрослых в культурно-просветительской работе; организации культурного пространства; повышении культурно-образовательного уровня различных групп населения, разработке стратегии просветительской деятельности; разработке и реализации культурно-просветительских программ с учетом специфики преподаваемого предмета и особенностей региона.

С целью реализации полифункциональной подготовки студентов ЕГФ СГСПУ внесены существенные изменения в учебные планы подготовки бакалавров и магистров педагогического образования. Наряду с дисциплинами предметной подготовки, модулями психологии, педагогики и методики обучения включен целый ряд новых дисциплин и курсов по выбору студентов. Среди них на уровне бакалавриата следует отметить «Информационно-коммуникационные технологии в образовании», «Основы комплексного сопровождения детей с ограниченными возможностями здоровья», «Организация воспитательной работы в условиях детского оздоровительного лагеря», «Деятельностный подход в обучении биологии», «Основы исследовательской деятельности в области естественнонаучного образования», «Современные средства оценивания результатов обучения»; на уровне магистратуры - магистерская программа «Биологическое образование»: «Методология и методы научного исследования», «Информационные технологии», «Инклюзивное образование», «Современные образовательные технологии в обучении биологии», «Организация учебно-исследовательской и проектной деятельности учащихся по биологии», «Диагностика и оценка качества образовательного процесса по биологии», «Проектирование образовательного процесса по биологии», «Дистанционное обучение биологии», «Формирование универсальных учебных действий в процессе обучения биологии», «Воспитание и социализация учащихся в процессе обучения биологии», «Коррекционная работа учителя биологии», «Организация внеурочной деятельности учащихся по биологии»; магистерская программа «Управление учебно-воспитательным процессом в системе общего образования»: «Стратегическое и оперативное управление образовательным процессом», «Управление качеством образовательного процесса», «Обзор лучших практик управления образовательным процессом», «Деонтология в образовании», «Безопасность межконфессиональных и межэтнических отношений» и другие.

Полифункциональная подготовка будущих учителей осуществляется в рамках учебных и производственных практик, учебно- и научно-исследовательской работы студентов, проведения государственной итоговой аттестации, а также в процессе подготовки публикаций, участия в студенческих олимпиадах, конференциях и конкурсах. На ЕГФ СГСПУ работают студенческие научные кружки и группы, проводятся ежегодные внутривузовские студенческие предметные олимпиады, научные конференции и конкурсы, издается межвузовский сборник научно-исследовательских работ студентов «Globularia» $[18,19,20]$.

Реализуя методику полифункциональной подготовки будущих учителей, было проведено анкетирование выпускников ЕГФ СГСПУ. В анкетировании приняли участие 42 человека. Судя по ответам на первый вопрос, 91,3\% выпускников остались довольны результатами своей профессиональной подготовки в вузе. $8,7 \%$ - затруднились ответить на этот вопрос. Отрадно, что ни один из опрошенных не дал отрицательный ответ. Это говорит о достаточно высоком качестве подготовки будущих учителей на факультете.

Ответы на второй вопрос анкеты выявили недостатки в подготовки выпускников по психологии. На это указали 47,8\% респондентов. 17,4\% опрошенных считают недостаточной подготовку по педагогике, $13 \%$ - по методике биологии, 8,7\% - по биологии и $21,7 \%$ - по экологии. Как видно из ответов, есть над чем задуматься кафедре педагогики и психологии, а также кафедре биологии, экологии и методики обучения.

У 69,6\% выпускников укрепился интерес к учительской профессии за годы обучения в вузе. Об этом свидетельствуют ответы на третий вопрос анкеты. Однако 26,1\% опрошенных затруднились ответить на этот вопрос, а 4,3\% респондентов дали на него и вовсе отрицательный ответ.

Ответы на четвертый вопрос говорят о том, что обучение в вузе позволило убедится выпускникам в наличии у них способностей к учительской профессии. На этот вопрос положительный ответ дали $87 \%$ респондентов. Несмотря на то, что $13 \%$ опрошенных затруднились ответит на этот вопрос, можно сделать вывод о том, что в педагогический вуз идут не случайные люди, а те, кто имеет определенные способности и желание работать в сфере образования.

Пятый вопрос позволил выявить, формированию каких профессиональных качеств личности учителя способствовало обучение в вузе. $60,9 \%$ выпускников указали на овладение обучающей функцией, 69,9\% на овладение воспитательной функцией, 47,8\% - на овладение методической функцией, 43,5\% - на овладение исследовательской функцией, 30,4\% - на овладение развивающей функцией, 26,1\% - на овладение культурно-просветительской функцией, по 13\% 
Семенов А.А., Соловьева В.В., Яицкий А.С.

овладели проектной и управленческой функциями и меньше всего опрошенных овладели коррекционной функцией $(8,7 \%)$. Как видно из ответов респондентов, они еще достаточно слабо подготовлены к реализации отдельных функций педагога. Следовательно, на это нужно обратить особое внимание в рамках полифункциональной подготовки будущих учителей.

Ответы на шестой вопрос свидетельствуют, что только 65,2\% выпускников планируют связать свою профессиональную деятельность с работой в школе. $17,4 \%$ респондентов затруднились с ответом и такое же количество опрошенных дали отрицательный ответ.

$86,2 \%$ выпускников осознают трудности работы учителем.

$56,5 \%$ выпускников готовы заимствовать опыт своих старших коллег, $47,8 \%$ респондентов намечают преодолевать недостатки в своей профессиональной подготовке через курсы повышения квалификации, по 26,1\% опрошенных планируют это делать через самообразование и творческое преодоление трудностей.

Проведенное анкетирование не претендует на выяснение истинного положения полифункциональной подготовки будущих учителей. Оно лишь намечает некоторые пути работы по совершенствованию профессиональной подготовки студентов педагогического вуза.

В заключении следует отметить о важности продолжения разработки методики полифункциональной подготовки будущих учителей, ее совершенствовании, теоретико-методологическом обосновании и объективной проверке в условиях педагогического эксперимента.

\section{СПИСОК ЛИТЕРАТУРЫ:}

1. Проект профессионального стандарта педагога (состав обобщенных трудовых функций, трудовых функций и перечень трудовых действий в соответствии с Национальной системой учительского роста) [Электронный ресурс] // http://стандартпедагога.рф/ view_3/index.html?page $=1$.

2. Профессиональный стандарт. Педагог (педагогическая деятельность в сфере дошкольного, начального общего, основного общего, среднего общего образования) (воспитатель, учитель). Утвержден приказом Министерства труда и социальной защиты Российской Федерации от 18.10.2013 г. № 544н // Российская газета - Федеральный выпуск, № 6261 (285). 18.12.2013.

3. Федеральный государственный образовательный стандарт высшего образования. Уровень высшего образования. Бакалавриат. Направление подготовки 44.03.01 Педагогическое образование. Утвержден приказом Министерства образования и науки Российской федерации от 04.12.2015 г. № 1426 [Электронный ресурс] // http://минобрнауки.рф/документы/ 7995.

4. Федеральный государственный образовательный стандарт высшего образования. Уровень высшего образования. Бакалавриат. Направление подготовки 44.03.05 Педагогическое образование (с двумя профилями подготовки). Утвержден приказом Министерства образования и науки Российской федерации от 09.02.2016 г. № 91 [Электронный ресурс] // http://минобрнауки.рф/документы/8073.
5. Федеральный государственный образовательный стандарт высшего образования. Уровень высшего образования. Магистратура. Направление подготовки 44.04.01 Педагогическое образование. Утвержден приказом Министерства образования и науки Российской федерации от 21.11.2014 г. № 1505 [Электронный peсурс] // http://минобрнауки.pф/ документы/5034.

6. Конституция Российской Федерации: офиц. текст. М.: Просвещение, 2009. 40 с.

7. Федеральный закон от 29 декабря 2012 г. № 273-Ф3 «Об образовании в Российской Федерации» // Российская газета - Федеральный выпуск. № 5976 (303). 31.12.2012.

8. Галустян О.В. Система полифункционального контроля профессиональной подготовки компетентного специалиста в высшей школе: дис. ... д-ра пед. наук: 13.00.08. Воронеж, 2016. 432 с.

9. Гончарова Ю.А. Полифункциональная система оценивания в образовательном процессе вуза // Актуальные проблемы обучения и воспитания школьников и студентов в образовательном учреждении: сборник научных статей, выпуск 5 / под ред. И.Ф.Бережной, С.В.Поповой. Воронеж: Издательскополиграфический центр ВГУ, 2011. С. 27-39.

10. Жаркова О.С. Проблема универсальной (полифункциональной) подготовки учителя музыки на современном этапе (Джазовое музицирование как компонент учебной работы в музыкально-исполнительских классах): дис. ... канд. пед. наук: 13.00.02. M., 1998. $201 \mathrm{c}$.

11. Кашликова Т.В. Формирование полифункциональной профессиональной готовности специалиста к социальной работе с семьей: дис. ... канд. пед. наук: 13.00.08. М., 2012. 274 с.

12. Кузьмина Н.В. Очерки психологии труда учителя. Л.: Ленинградский университет, 1967. 183 с.

13. Основина Т.Ю. Подготовка студентов к полифункциональной социально-управленческой деятельности: дис. ... канд. пед. наук: 13.00.08. Екатеринбург, 2009. 346 с.

14. Печерская А.Б. Полифункциональная подготовка будущих учителей музыки: на материале работы в концертмейстерском классе: дис. ... канд. пед. наук: 13.00.02. М., 2009. 167 с.

15. Рыков Н.А., Щербаков А.И. Профессиограмма учителя биологии средней общеобразовательной школы // Научно-педагогические основы подготовки учителя биологии: постоянно действующий межвузовский республиканский тематический научный сборник. Выпуск 1. Профессионально-педагогическая направленность в системе преподавания специальных дисциплин на факультетах естествознания. Л.: ЛГПИ им. А.И.Герцена, 1973. С. 17-61.

16. Хасанов С. Педагогические основы полифункциональной подготовки студентов к профессиональной деятельности: дис. ... канд. пед. наук: 13.00.01. Худжанд, 2001. 147 с.

17. Чоросова О.М. О формировании полифункциональности педагога в условиях информационнокоммуникационной среды // Труды Большого Московского семинара по методике раннего обучения информатике [Электронный ресурс] // http://ito.edu.ru/ sp/publi/publi-0-chorosova-2012osen.html.

18. Примерная основная образовательная программа основного общего образования [Электронный ресурс] // http://docme.ru. 
19. Семенов А.А. Методическая подготовка учителей биологии в контексте ФГОС общего образования и профессионального стандарта педагога // Биологическое и экологическое образование в школе и в вузе: теория, методика, практика: сборник статей междунар. науч.-практ. конф. (21-24 ноября 2016 г.). Вып. 15, Санкт-Петербург / под ред. проф. Н.Д. Андреевой. СПб.: Свое издательство, 2016. С. 174-176.
20. Семенов А.А., Носова Т.М., Колыванова Л.А. Подготовка магистров биологического образования к осуществлению научно-исследовательской деятельности // Інноваційний розвиток вищої освіти: глобальний та національний виміри змін: матеріали III Міжнародної науково-практичної конференції (6-7 квітня 2016 року, м. Суми). Суми: Вид-во СумДПУ імені А.С.Макаренка, 2016. Т. 1. С. 177-181.

\title{
MULTIFUNCTIONAL TRAINING OF FUTURE TEACHERS IN CONTEXT OF FEDERAL STATE EDUCATIONAL STANDARDS AND PROFESSIONAL STANDARD OF PEDAGOGUE
}

(C) 2017

Semenov Alexander Alexeevich, candidate of biological sciences, associate professor, head of Chair of Biology, Ecology and Methods of Teaching

Solovieva Vera Valentinovna, doctor of biological sciences, professor of Chair of Biology, Ecology and Methods of Teaching

Yaitsky Andrey Stepanovich, senior lecturer of Chair of Biology, Ecology and Methods of Teaching Samara State University of Social Sciences and Education (Samara, Russian Federation)

Abstract. Pedagogical activity is multifunctional in nature. Multifunctionality of the teacher's activity is obliged by the requirements of the Federal State Educational Standards of Higher Education as well as the teacher's professional standard. Multifunctional training of future teachers is the process (and result) of mastering by the pedagogic bachelors and masters of set of competencies aimed at fulfilling various teacher functions. There are six basic functions of the modern teacher identified: pedagogical, project, research, methodological, managerial and culturaleducational. The pedagogical function is complex in nature and includes a number of other functions: tutoring, education, developing and correction. All of them are interrelated. The article outlines characteristics of mentioned above functions, describes the track record of training of future teachers at Faculty of Natural Sciences and Geography of Samara State University of Social Sciences and Education as part of baccalaureate and magistracy programs of pedagogical education. This consists of updating of courses content that are implemented according to the student selection, development and realization of new ones, organization and execution of training and production practices, educational and research works of students, scientific conferences, student competitions and olympiads, publication of scientific collected papers (including student ones). Article also presents the results of surveys of graduates on the quality of their preparation for the various teaching functions.

Keywords: pedagogical education; multifunctionality; multifunctional training; future teachers; bachelors; masters; students; pedagogical activity; pedagogue; teacher; functions of teacher; Federal State Educational Standard; Professional Standard of Pedagogue.

УДК 378.6

Статья поступила в редакцию 02.06.2017

\section{МОДЕЛИРОВАНИЕ КУРСА ИНТЕГРИРОВАННЫХ ЗАНЯТИЙ ПО АНГЛИЙСКОМУ ЯЗЫКУ И ЛИТЕРАТУРЕ В ЮРИДИЧЕСКОМ ВЕДОМСТВЕННОМ ВУЗЕ}

(C) 2017

\author{
Скобелева Оксана Олеговна, кандидат педагогических наук, \\ заместитель начальника кафедры философии и общегуманитарных дисциплин \\ Самарский юридический институт ФСИН России (2. Самара, Российская Федеращия)
}

\footnotetext{
Аннотация. В данной статье рассматривается проблема совершенствования языковых и культурологических навыков обучающихся посредством внедрения в образовательный процесс интегрированных занятий по иностранному языку и литературе. Интеграция культур при обучении курсантов ведомственных юридических вузов является важным элементом подготовки специалистов, компетентность которых во многом определяется не только профессиональными навыками, но и умениями пользоваться иностранным языком в рамках установления контактов с представителями других культур, умениями самостоятельно работать с научной и практической документацией и литературой, вести деловую переписку и переговоры. В работе обозначены основания разработки интегрированного курса английского языка и литературы, предложены серии занятий по межпредметным взаимодействиям. Проведенные исследования показали, что межпредметные связи на занятиях иностранного языка положительно сказываются на качестве образовательного процесса: расширяется кругозор курсантов, повышается мотивационная сторона обучения, активизируется учебно-исследовательская деятельность, формируется нравственное воспитание, развиваются коммуникативные навыки обучаемых. Полученные результаты свидетельствуют о необходимости разработки подобных занятий в рамках любой специализации и направленности, так как интегрированные курсы существенно расширяют не только познавательные, но и языковые навыки обучающихся.

Ключевые слова: интеграция; интегративные взаимодействия; межпредметные связи; занятие по иностранному языку; произведение художественной литературы; коммуникативная компетенция; курсант; юридический вуз; уровень знаний; культурологический контекст; профессиональная подготовка; коммуникация; лексические единицы.
} 